\title{
The Quantifying, Predicting, and Exploiting Uncertainty Program: Exploring Oceanographic Processes in a Complex Bathymetric Shelf/Slope Environment affected by the Kuroshio
}

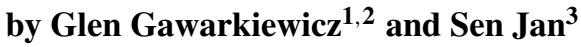

\begin{abstract}
We will describe the multi-disciplinary international program, Quantifying, Predicting and Exploiting Uncertainty, which consisted of observations, modeling and remote sensing studies focused on a region northeast of Taiwan in the East China Sea. We focus on results on the physical oceanographic and biogeochemical processes. Concurrent observations of acoustic propagation also occurred during the intensive observation period. This program was a joint Taiwan-U.S. effort involving four different ships sampling the continental shelf and slope during August-September, 2009. Primary goals of the program included 1) studying the structure and variability of the Cold Dome, a cool cyclonic feature frequently present in summer over the continental shelf; 2) examining the strength of upwelling from the continental slope to the shelf and the associated biogeochemical fluxes; and 3) establishing the predictability and structure of Kuroshio Intrusions onto the continental shelf. In addition, the program examined the characteristics of internal tides and waves in this region. During the intensive observations in Aug.-Sept., 2009, the continental shelf was strongly impacted by the passage of Typhoon Morakot across the region. Due to heavy rainfall throughout southern Taiwan, fresh water plumes impacted the continental shelf for several weeks after the typhoon. Numerical modeling studies show a pronounced cooling of $3^{\circ} \mathrm{C}$ after the storm, which are associated with significant fluxes of nitrate and phosphate onto the continental shelf. Both internal tides over the continental slope, as well as internal waves over the shelf and slope are characterized and compared with recent observations in other regions including the South China Sea and the northeastern U.S. off New Jersey. A particularly striking aspect of this region is the profusion of potential internal wave generation sites due to the presence of three different canyons with complex and steep bathymetry.
\end{abstract}

\section{Introduction}

The Quantifying, Predicting and Exploiting Uncertainty (QPE) Program was a multidisciplinary international effort to examine uncertainty in both ocean circulation models,

1. Woods Hole Oceanographic Institution, Woods Hole, Massachusetts 02543, USA.

2. Corresponding author e-mail: ggawarkiewicz@whoi.edu

3. Institute of Oceanography, National Taiwan University, No. 1, Sec. 4, Roosevelt Road, Taipei, 10617, Taiwan R.O.C. 
as well as acoustic propagation models. The initiative was a joint Taiwan-U.S. endeavor involving an intensive field campaign in Aug.-Sept., 2009. In addition, longer-term drifter measurements and extensive analysis of remote sensing imagery and numerical modeling, including real-time forecasts of circulation and associated uncertainty, complemented the intensive field program. The papers presented in this issue focus on the circulation and biogeochemistry. The results on acoustic propagation will appear in other journals. Some preliminary results from the QPE program have previously appeared in Gawarkiewicz et al. (2011).

The primary study area is northeast of Taiwan over the continental shelf and slope (Fig. 1). This geographical area was chosen because of the diversity and complexity of the oceanographic processes on a variety of time scales. The Kuroshio flows northward east of Taiwan into the East China Sea where it encounters the bathymetry at the edge of the continental shelf and shifts its orientation Northeastward, roughly following bathymetry. An overview of the circulation in the region is given in Jan et al. (2011). In addition, there is northward flow west of Taiwan through the Taiwan Strait, therefore the mean flow over the continental shelf northeast of Taiwan is generally to the northeast (Chern and Wang, 1992; Jan et al., 2006). Sometimes the Kuroshio penetrates onto the shelf, (e.g. Liu et al., 1992; Hsueh et al., 1992; Tang et al., 1999) generating strong currents over the continental shelf.

A particularly striking feature in this area is the Cold Dome. This was first identified by Chern et al. (1990) and was studied extensively by Tang et al. (2000). This feature is evident as a local minimum in sea surface temperature and primarily occurs during summer months. The diameter of the Cold Dome is roughly $100 \mathrm{~km}$, but its area changes substantially over relatively short time scales (Jan et al., 2011). There is a weak cyclonic circulation over the continental shelf that is associated with the denser water within this feature. The Cold Dome is evident in climatological temperature fields (Fig. 2). Developing an understanding of the variability of the Cold Dome was viewed as an important goal that would facilitate the interpretation of the spatially and temporally varying fields of uncertainty for both the ocean circulation models, as well as the acoustic propagation models.

We will briefly describe the science questions and background of the QPE program. Next we will discuss the papers in this volume that address the impact of Typhoon Morakot, which occurred early during the intensive observation period. This includes consideration of fresh water pulses from the river run-off after the typhoon arrived on the continental shelf northeast of Taiwan (Jan et al., 2013), numerical modeling of the upwelling and cooling that occurred over the continental shelf after the Typhoon (Tsai et al., 2013), and the effect of Typhoon Morakot on the biogeochemistry and nutrient dynamics of the continental shelf (Hung et al., 2013). Next, we will present the primary findings from the papers that examine the internal tides and internal waves (Lien et al., 2013 and Duda et al., 2013). Finally, longterm drifter observations are used to describe the conditions which led to Kuroshio intrusions over the continental shelf (Vélez-Belchí et al., 2013). We will conclude by briefly listing the major findings of the program and suggest three major research avenues for future studies. 

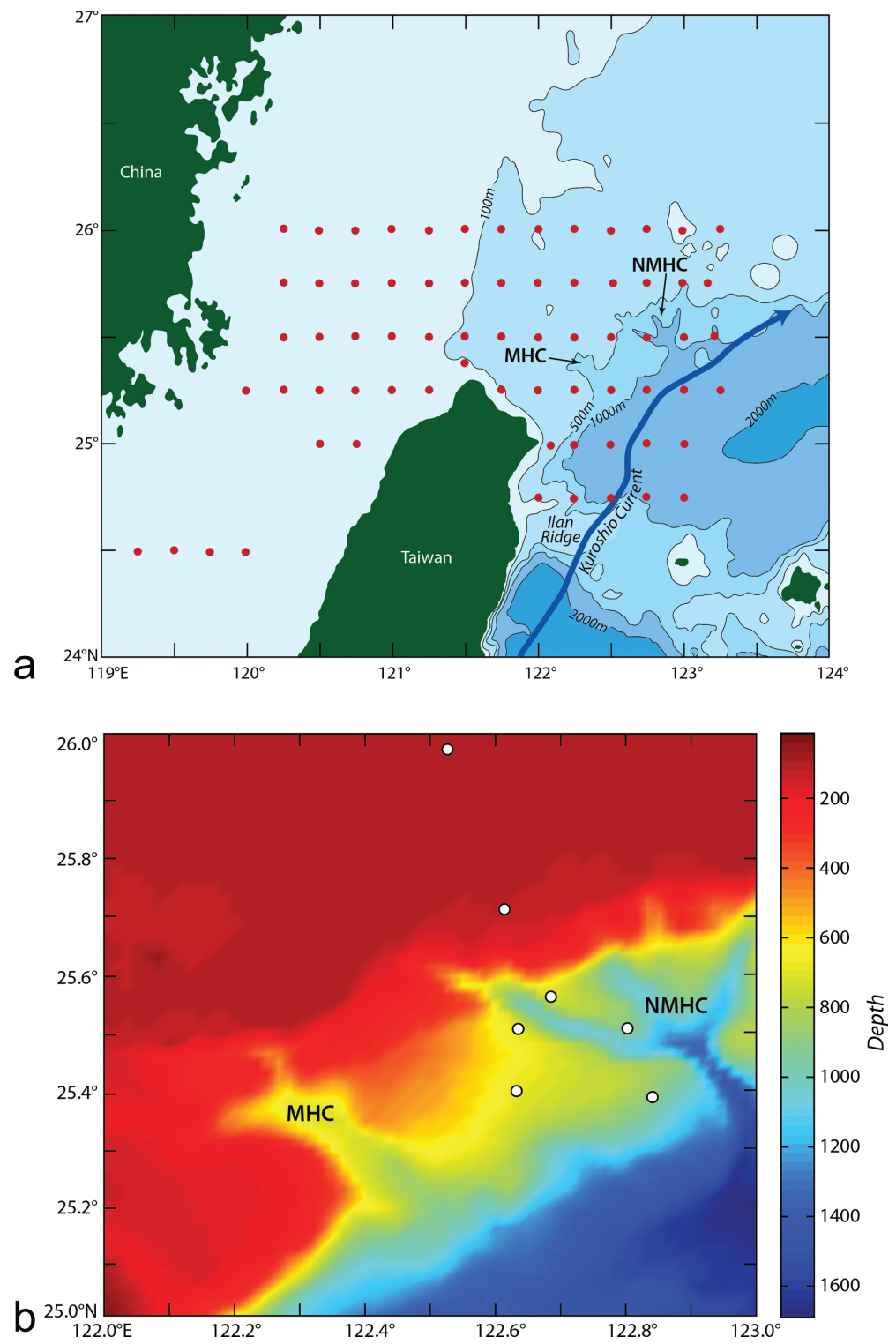

Figure 1. a) A map of the primary study area during the intensive field operations in Aug.-Sept., 2009. MHC denotes Mien-Hua Canyon and NMHC denotes North Mien-Hua Canyon. The Ilan Ridge is south of the primary study area. The red dots denote CTD stations from one of the broad scale surveys. The mean position of the core of the Kuroshio in summer is marked by the blue line, taken from an archive of historical shipboard ADCP data. b) A zoomed in map of the two canyons. The white dots mark the position of moorings which were deployed during the intensive observation period. 


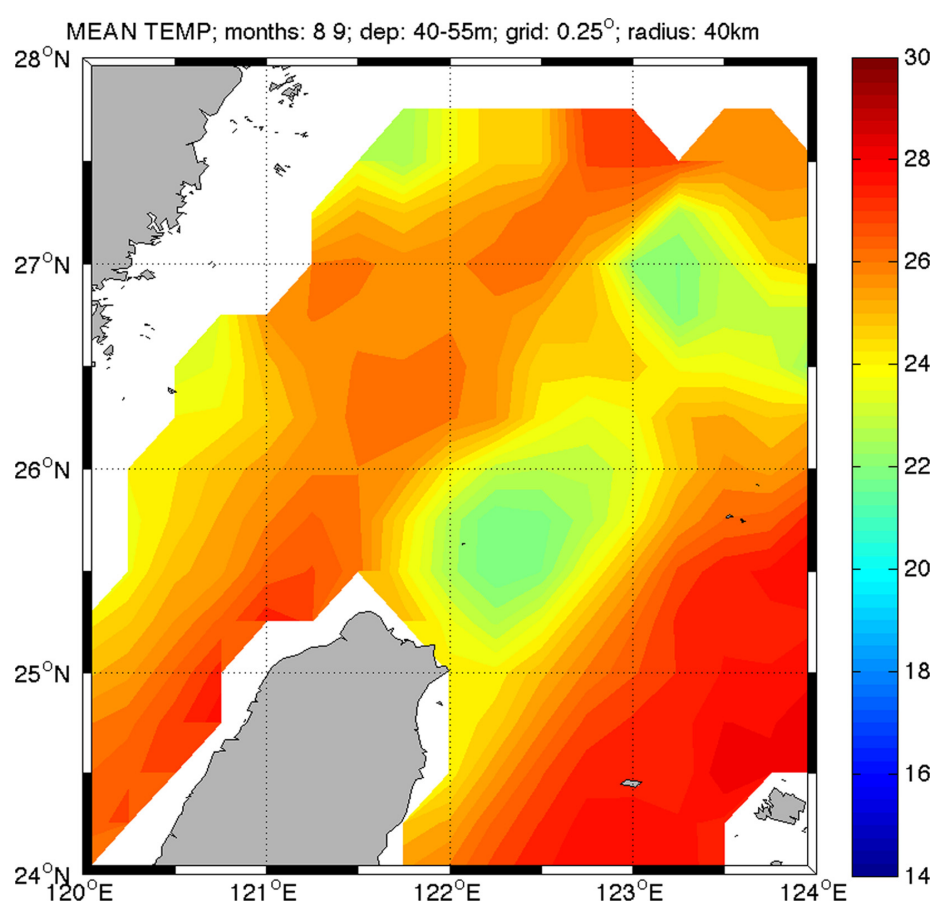

Figure 2. A climatological temperature field for the area north of Taiwan for the Aug.-Sept. time period. Data from depths of $40-55 \mathrm{~m}$ are averaged from all available data from the Taiwanese hydrographic database. The Cold Dome is the relatively cool $\left(22^{\circ} \mathrm{C}\right)$ feature centered at $25.5^{\circ} \mathrm{N}$ $122.5^{\circ} \mathrm{E}$.

\section{Science questions and background}

The science questions that were the main focus of the oceanographic portion of this program were as follows:

- What is the structure and variability of the Cold Dome over the outer continental shelf northeast of Taiwan?

- How predictable are Kuroshio excursions onto the shelf in this region?

- How predictable are internal tides and internal waves in this region?

- How well can we forecast the uncertainty in model predictions of temperature, salinity, density, nutrient concentration, sound speed and velocity within a region of complex bathymetry and oceanographic processes?

The Cold Dome has been a subject of a number of previous studies, and yet the role of local and monsoon wind forcing, the proximity of the Kuroshio, and the time scales for formation and persistence of this cyclonic feature have been controversial. Tang et al. (1999) provided a synoptic survey that clearly defines the cyclonic nature of the circulation 
over the continental shelf and identifies sub-surface Kuroshio water as the origin of the colder water on the continental shelf. The observations in this survey indicate that Kuroshio intrusions are possible in the summer. Prior to the Tang et al. (1999) study, the prevailing opinion was the Kuroshio intrusions were associated with the winter monsoon, when the wind-driven transport in the surface mixed layer is directed onshore. More recently, Chang et al. (2009) examined the relative contributions from the Kuroshio and local wind stress curl to upwelling over the continental shelf. They found the winter monsoon leads to upwelling in the upper $30 \mathrm{~m}$ being predominant relative to the summer, but that upwelling from $100 \mathrm{~m}$ depth was larger during the summer due to the Kuroshio.

The behavior of the Kuroshio in this region is complex because the western boundary current encounters the shallow bathymetry of the continental shelf, and thus shifts its orientation to eventually run parallel to the slope bathymetry. A simple model for the Kuroshio intrusion process appeared in Hsueh et al. (1992), which considers the case of a current encountering a step shelf. Previous studies have also examined the Kuroshio east of Taiwan and have shown that there is a 100-day fluctuation, which is tied to the westward advection of large eddies (Zhang et al., 2001; Lee et al., 2001). Further to the northeast, a linear stability analysis and observations indicate that the most unstable waves of the Kuroshio have periods of 11 days consistently, as well as periods of seven and 16 days more intermittently (James et al., 1999). These observations are northeast of the QPE study area, but are relevant to considering the time scales for forcing of Kuroshio intrusions.

The continental shelf and slope northeast of Taiwan has not been studied as closely with regard to internal tides and non-linear internal waves as the South China Sea. With programs such as The Asian Seas International Acoustics Experiment (ASIAEX) in the South China Sea (Ramp and Tang, 2011), there have been significant efforts to examine the structure and predictability of trans-basin waves originating in Luzon Strait and their evolution across the central basin. The situation northeast of Taiwan is more complicated for a variety of reasons. First, the bathymetry is more complex due to the presence of the three canyons, which have different geomorphologies. Second, the proximity of the Kuroshio ensures that the stratification over the continental slope changes on a wide variety of time scales. The Kuroshio may also be a source of internal waves in this region (Rainville and Pinkel, 2004). Third, features over the continental shelf such as the Cold Dome and northward flow through Taiwan Strait can lead to significant changes in stratification over the continental shelf. Internal waves in this region have been examined through remote sensing (e.g. Liu et al., 1998; Hsu et al., 2000), but in situ observations have been limited. Part of the difficulty in making measurements in this region is the high level of fishing activity, which makes mooring deployments over extended periods of time difficult.

It was anticipated that because of the Aug.-Sept. time frame for the intensive observation period there was a possibility of typhoon passage near the study area. It is known that typhoons northeast of Taiwan result in lower surface temperatures due to both vertical mixing, as well as enhanced upwelling near the shelf-break (Tsai et al., 2008). However, the entire field program in 2009 was strongly impacted by the passage of Typhoon Morakot, 
which caused exceptionally large amounts of rainfall over Taiwan. The papers dealing with the impacts of Typhoon Morakot are discussed in the next section.

A key element of the field program was real-time forecasting of thermohaline and velocity fields with the associated uncertainty. Data were communicated from the ships in near realtime back to MIT (Massachusetts Institute of Technology) and the ocean modeling group lead by P. Lermusiaux computed ensemble forecasts of up to five days. An overview of issues and methodologies for calculating uncertainty in ocean models appears in Lermusiaux et al. (2006). An example of a typical forecast during the intensive observation period and the associated uncertainty appears in Figure 3. Comparison of the uncertainty forecasts to the probability density functions of the model errors is presently underway, and will be reported in the future. Examples of the model forecasts and their use in forecasting acoustic propagation appear in Lermusiaux et al. (2011).

\section{Impacts of Typhoon Morakot}

The field operations during 2009 were strongly affected by Typhoon Morakot. This Typhoon passed Taiwan on Aug. 6-8, 2009 and resulted in the highest rainfall in Taiwan from a typhoon in 50 years. The rainfall led to flooding along with extensive damage, particularly in the mountains in the southern half of Taiwan, and the loss of many lives. Morakot was a category 2 typhoon, but the extensive flooding in mountains lead to a rapid increase in outflow from rivers in the south. The rainfall distribution over Taiwan and the subsequent river runoff from the Typhoon is shown in Figure 4. The meteorological fields associated with Typhoon Morakot have been used to model storm surges and the wave field by Lee et al. (2013).

Jan et al. describes the impact of the Typhoon on the circulation and hydrography of the continental shelf northeast of Taiwan. Using three separate broad scale surveys north of Taiwan with two ships in each survey, they identify buoyant freshened plumes arriving on the continental shelf northeast of Taiwan. Near surface waters were $1 \mathrm{~g} / \mathrm{kg}$ fresher than ambient shelf waters. Four separate pulses of fresh water were identified from different river outflows in the southwest of Taiwan. Peak daily river flow from the largest of the southern rivers (Gaoping River) was $18,000 \mathrm{~m}^{3} \mathrm{~s}^{-1}$ compared to a normal summer flow of $200 \mathrm{~m}^{3}$ $\mathrm{s}^{-1}$.

Tsai et al. model the upwelling response as a result of the Typhoon forcing over the continental shelf northeast of Taiwan. In particular, they examine the northward flow of sub-surface Kuroshio water shortly after the Typhoon passage. They find that over two days there is enhanced upwelling of cold water, leading to as much as a $3^{\circ} \mathrm{C}$ cold anomaly over the continental shelf in the region normally associated with the Cold Dome. The cold water in this region persists, and a cyclonic circulation results that leads eventually to northeastward advection of this cyclonic eddy with the prevailing mean flows. A significant finding of this paper is that many of the processes commonly invoked for this region such as Cold Dome formation and circulation also occur, in a more energetic and accelerated fashion, 


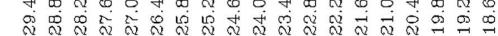

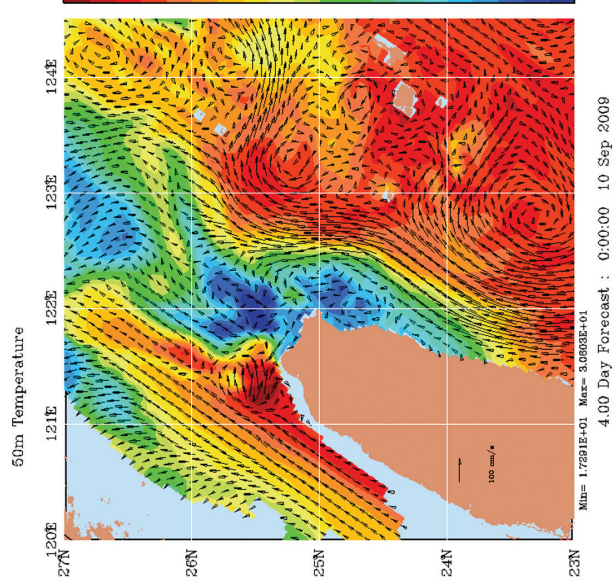

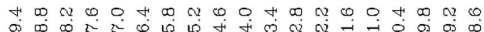

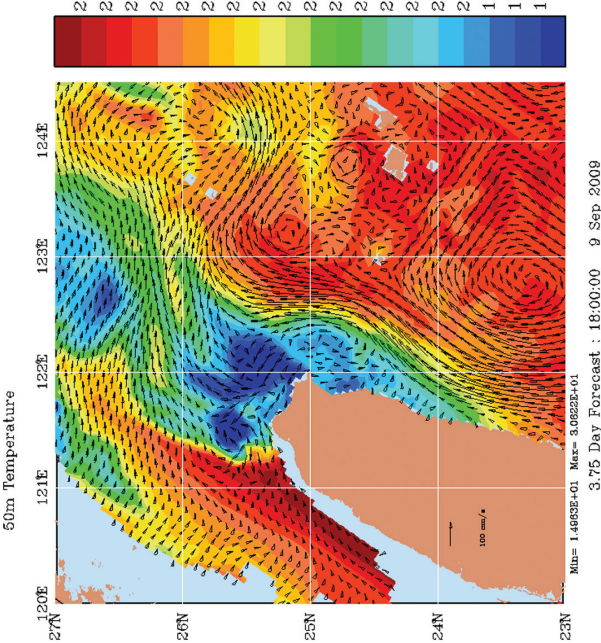

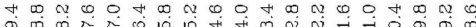

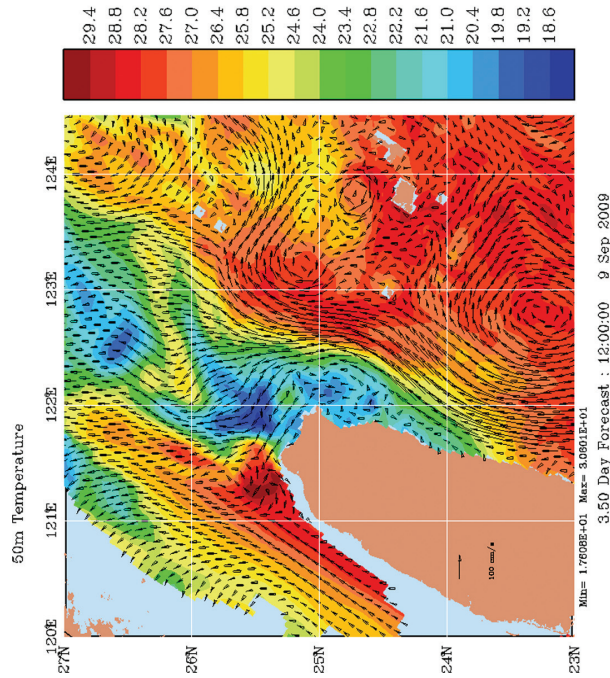

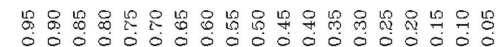
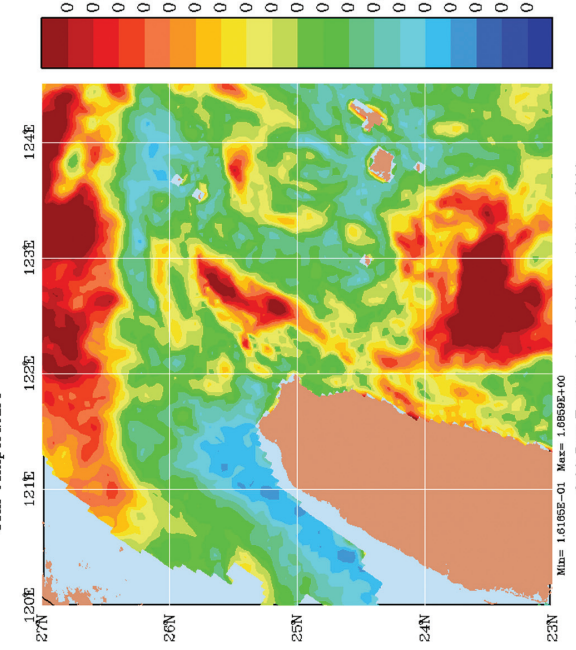

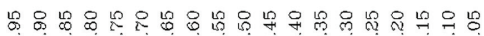
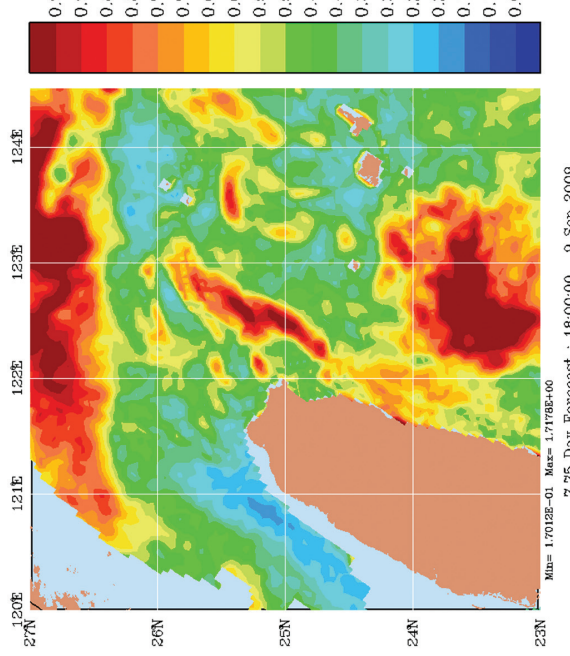

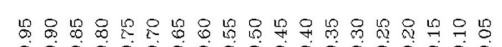
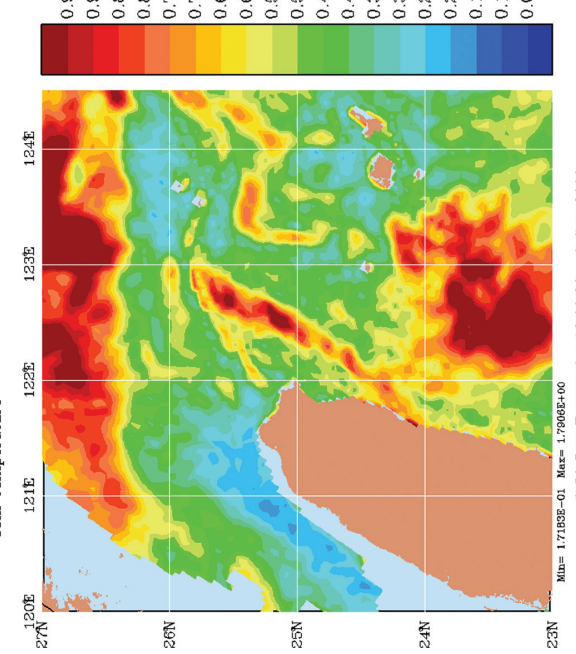

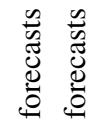

.

.

d)

은

苋

芯

는

हี

ฮี

ปั

$3 \pm$

Ð)

으

플

$\Xi . \cong$

i $\frac{\infty}{0}$

อ

范

官

ᄋิํㅇ

금

을

F

ด छ

范

ڤ

ᄒั

露

.

है

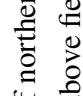

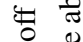

空

ङั

ठ휴

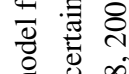

巳 $\infty$

छี

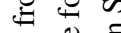

음



氙

泡

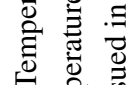

․ छ

光 
(a)

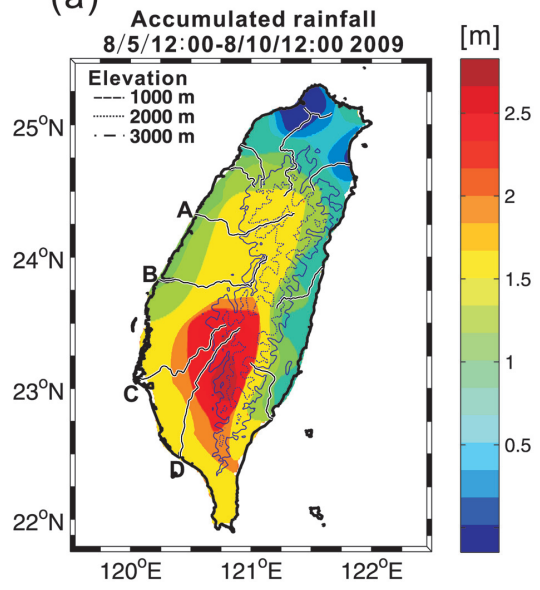

(b)

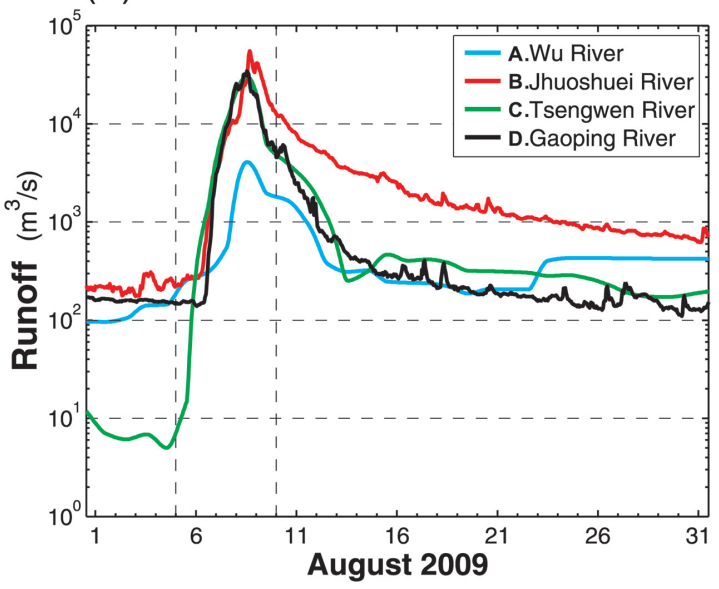

Figure 4. a) A map of rainfall distribution over Taiwan after Typhoon Morakot. The mountains in southern Taiwan received over $2 \mathrm{~m}$ of rain. b) A time series of river run-off for the four largest rivers in southwest Taiwan, showing the substantial increase in runoff after Typhoon Morakot. The figure is taken from Jan et al., this issue.

when a typhoon passes south of the continental shelf northeast of Taiwan. Furthermore, they demonstrate the upwelling is necessary to produce the observed cold temperature anomalies, and vertical mixing processes alone are not sufficient to obtain the observed temperature anomalies. Both sea surface temperature and sea surface height anomaly distributions are presented, which confirm the model results regarding the formation of a cold cyclonic eddy over the shelf and its subsequent advection to the northeast.

The impacts of Typhoon Morakot have profound consequences for the nutrient distributions and biogeochemical cycling over the continental shelf northeast of Taiwan. Hung et al. describes a series of observations throughout the summer of 2009 that span the time period before and after the Typhoon (Fig. 5). Typhoons in this region generally create upwelling of ambient nutrient-rich continental slope waters (not Kuroshio core water masses, but the denser underlying water mass) due to a combination of winds, currents and the complex bathymetry in this local area (Tsai et al., 2008). Hung et al. finds the Typhoon leads to a significant flux of nitrate and phosphate onto the continental shelf area northeast of Taiwan, $5.6 \times 10^{11} \mathrm{~g}-\mathrm{N} \mathrm{day}^{-1}$ and $7.8 \times 10^{10} \mathrm{~g}-\mathrm{P}$ day $^{-1}$, respectively. The fluxes associated with the Typhoon can account for $86 \%$ of the nitrogen needed to balance the summer nitrate budget and $87 \%$ of the phosphate needed to balance the summer phosphate budget. A key conclusion of this study is the nutrients upwelled onto the shelf from the subsurface Kuroshio water are by far the greatest source of nutrients, nearly two orders of magnitude larger than the contributions from the riverine inputs. A broad implication of this study is these extreme weather events play a significant role in the seasonal and annual budgets of 

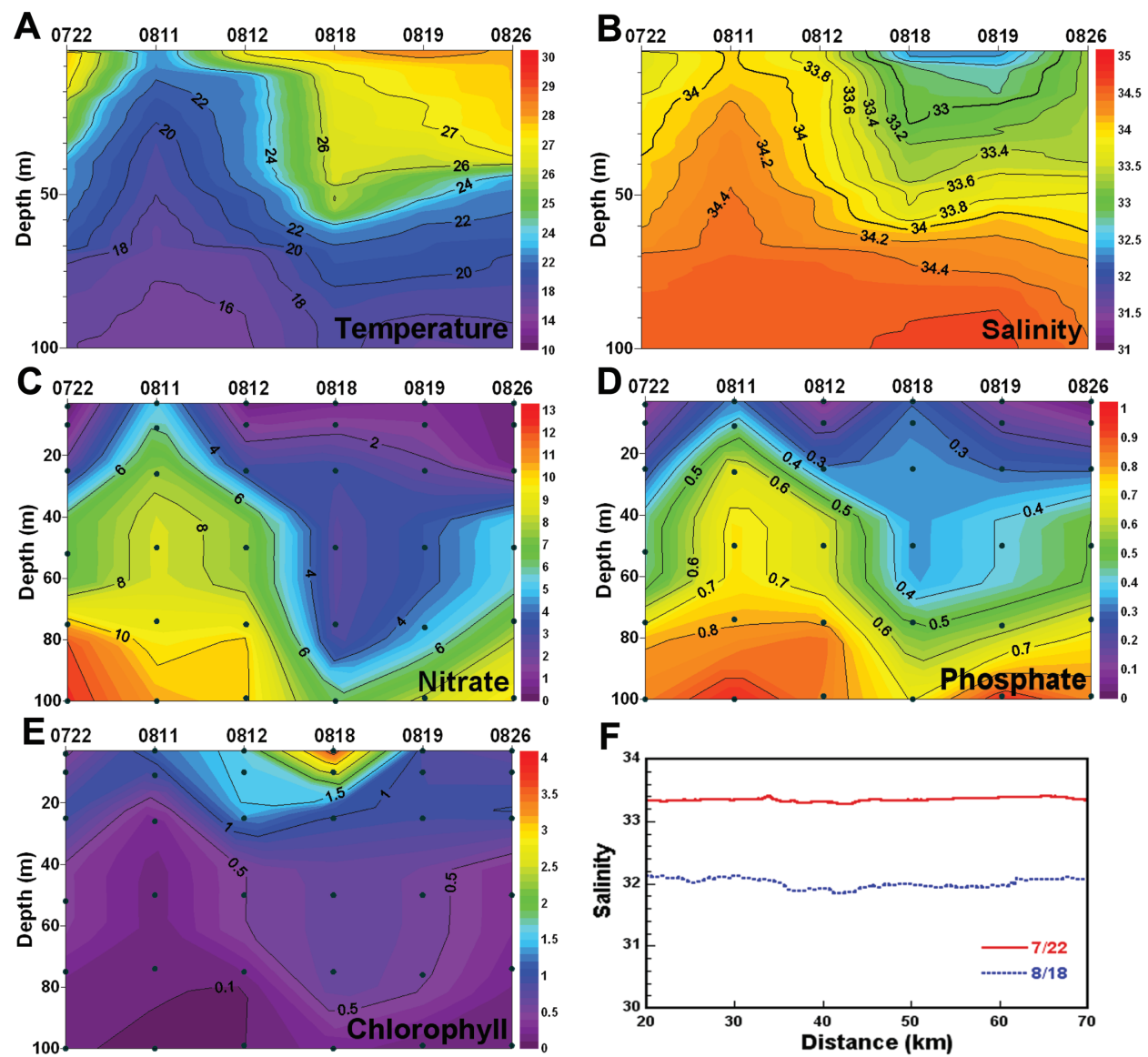

Figure 5. Time series of a) temperature b) salinity c) nitrate d) phosphate e) chlorophyll a and f) cross-shelf distribution of surface salinity from July 22 to Aug. 26, 2009. The time series are from $25.45^{\circ} \mathrm{N} 122.0^{\circ} \mathrm{E}$. This figure is taken from Hung et al., this issue.

nutrients in the East China Sea, and will be necessary to account for in studies that consider both inter-annual variability, as well as the impacts of climate change in this region.

\section{Barotropic and Baroclinic Tides and characteristics of internal waves}

The combination of steep and complicated bathymetry, strong currents and strong stratification leads to exceptionally complicated tidal and internal wave fields over the continental shelf and slope northeast of Taiwan. Two papers in this volume address the complexities and offer directions for future research. 
Lien et al. uses a combination of in situ moorings, freely drifting profilers (EM-APEX floats) and a baroclinic model with spatially invariant stratification and realistic bathymetry to address important issues related to the structure of the baroclinic tides. Lien et al. convincingly demonstrate there are large areas, particularly near the canyons, where the critical slope for internal wave generation is present (Fig. 6). They show that there is significant energy in high wave number baroclinic tides over the continental slope, with both upward and downward propagating energy. The interaction of the vertically propagating energy in these high wavenumber modes leads to patches of shear in the horizontal flow with vertical scales of order $50 \mathrm{~m}$. Surprisingly, from the EM-APEX float data, these bands of enhanced shear extend from the continental slope to the continental shelf and are coherent over horizontal scales of order tens of kilometers. These bands appear to be similar to those found farther east in the East China Sea by Rainville and Pinkel (2004), which appear to be propagating shoreward from the Kuroshio. These bands of enhanced shear may be important in exciting shear instabilities over the outer continental shelf and upper continental slope, and are clearly deserving of further study, particularly for their potential impact on biogeochemical cycling, nutrient transport and the development of thin layers for both phytoplankton and zooplankton.

In this paper baroclinic energy fluxes are calculated from the moorings and are compared to a baroclinic numerical model with realistic bathymetry and spatially invariant stratification. The largest energy fluxes occur over the upper continental slope and have a depth-integrated seaward energy flux of $3.0-10.7 \mathrm{~kW} \mathrm{~m}^{-1}$, compared to calculated fluxes of $1.0-7.2 \mathrm{~kW} \mathrm{~m}^{-1}$ from the numerical model. Possible reasons for the discrepancy with the model are discussed in the paper. Lien et al. also finds the energy in the internal wave continuum is six-13 times that of the Garrett-Munk model, strongly suggesting the energy cascade from strong inertial waves and internal tides in this area enhances internal wave energy levels compared to levels typical of the deep ocean.

Internal tides and non-linear internal waves in the study region are examined in Duda et al. using shipboard observations, remote sensing imagery and moorings over the continental shelf. In this study, a large amplitude $(50 \mathrm{~m})$ non-linear internal wave was observed by shipboard navigation radar over the continental slope, as well as by the ship's SIMRAD EK500 echo sounder (sonar). The internal wave was observed at the $580 \mathrm{~m}$ isobath, and was propagating to the northwest. This wave appears to have been a trans-basin wave likely generated over Ilan Ridge, located about $85 \mathrm{~km}$ south of the observed wave. The shape of the wave from the echo sounder data was compared to the solutions of the Dubreil-JacotinLong (DJL) non-linear wave equation and the ratio of the velocity to the phase speed was 0.53 , indicating that the wave has weak non-linearity. Calculation of the available potential energy of the wave indicates it is far less energetic than trans-basin waves in the South China Sea (e.g. Klymak et al., 2006), but more energetic than those observed on the New Jersey continental shelf (e.g. Shroyer et al., 2010).

Examination of internal wave amplitudes over the continental shelf from moorings at two sites at the $110 \mathrm{~m}$ and $130 \mathrm{~m}$ isobath, with the latter in close proximity to the shelfbreak, 

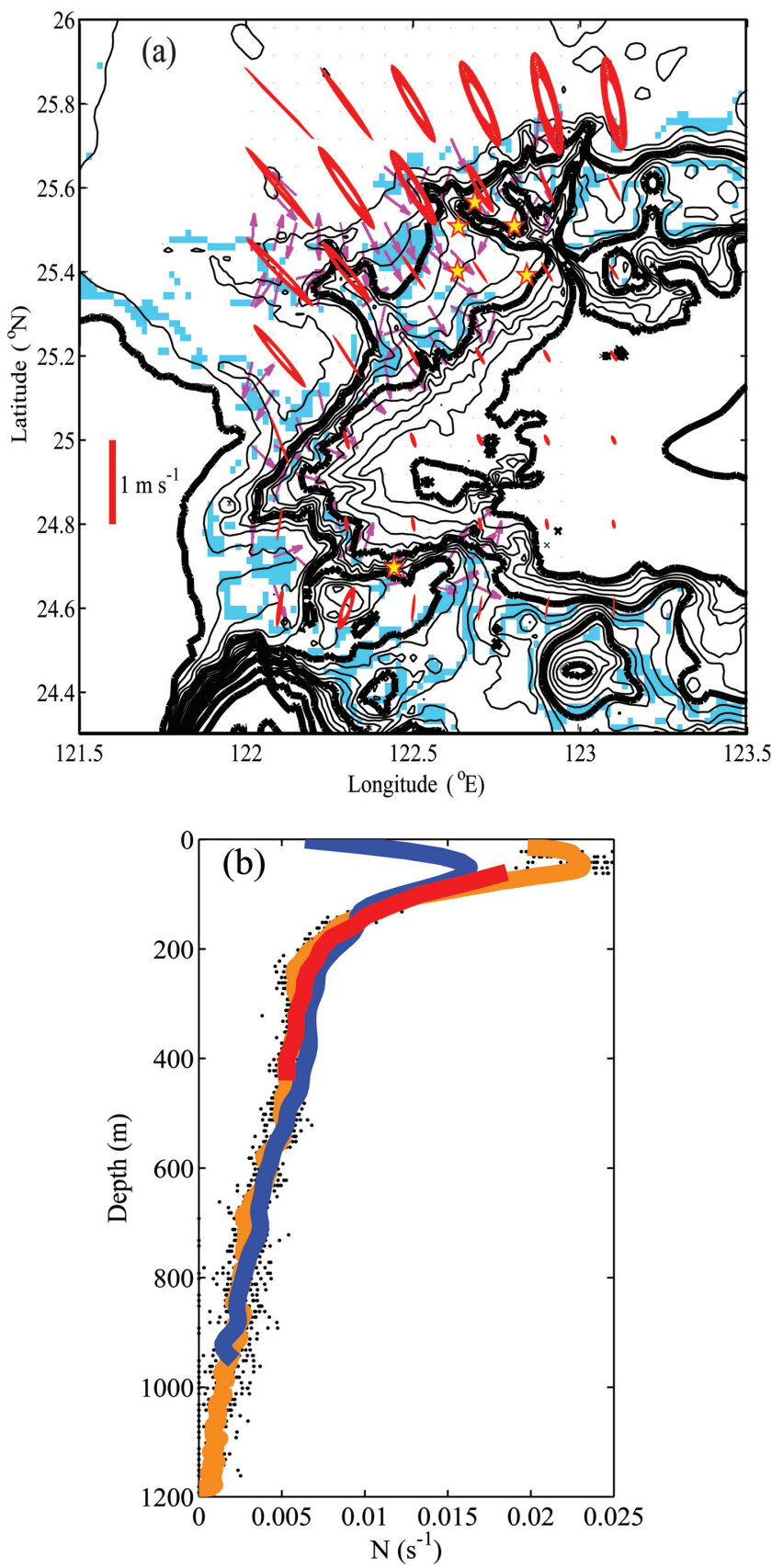

Figure 6. a) A map of critical slopes (cyan shading) where the ratio of the bottom slope to the internal wave characteristic slope is between 0.5 and 2 . Tidal ellipses for the barotropic tides are shown in red. b) Stratification for this region from historical data (blue curve), from EM-APEX float measurements (orange curve), and from moorings over the continental slope during the intensive observation period (red curve). Figure taken from Lien et al., this issue. 
indicate that there is a higher degree of non-linearity as the internal waves propagate into shallower water. One particular wave had a measured displacement of $34 \mathrm{~m}$ where the surface layer thickness was $35 \mathrm{~m}$, and thus the displacement was comparable to the upper layer thickness, indicating significant non-linearity. Over the shelf, SAR imagery indicates there are internal wave crests propagating in a wide range of directions over the continental shelf in this area, likely due to the large number of local generation sites (particularly near canyons) as well as the trans-basin waves arriving from Ilan Ridge. Selected time series showing non-linear internal waves at the $130 \mathrm{~m}$ isobath near the shelf-break appear in Figure 7.

The internal tide in the study area was intermediate in kinetic energy relative to the low energy levels observed previously off New Jersey and the high energy levels observed in the ASIAEX site in the South China Sea. The energy in the diurnal baroclinic tide was large relative to the energy level in the diurnal barotropic tide. The cause of this higher relative energy level for the diurnal internal tide is worthy of further investigation in the future.

\section{Large scale flows east of Taiwan and the predictability of Kuroshio Intrusions}

A particularly important aspect of the circulation on the continental shelf northeast of Taiwan is the interaction of the Kuroshio with the shelf flow, in particular in intrusions of Kuroshio water onto the continental shelf. Combining data from weekly near-surface drifter releases with objective mapping of sea level anomaly data, Velez-Belchi et al. examine the relationship between the northward transport in the Kuroshio and the frequency of Kuroshio intrusions onto the continental shelf. They classify two types of intrusions, which they identify as small and large, based on the distance of penetration across the shelf. The two types are defined by both their cross-shelf penetration distance across the shelf, as well as the along-shelf location where the Kuroshio crosses the shelfbreak.

An elegant aspect of the results in this paper is the development of a relationship between the sea level anomalies east of Taiwan and the northward transport of the Kuroshio. The authors use earlier mooring data from Johns et al. (2001) with the concurrent sea level anomalies to develop a long-term time series of Kuroshio transport east of Taiwan. The sea level anomalies were examined to determine the point of maximum zero lag correlation between the sea level anomalies and the direct estimate of transport from the mooring data. The temporal values of the height anomaly at the point of maximum zero lag correlation, which is to the southwest of the Ryukyu Islands, is then used to evaluate the transports during the individual Kuroshio intrusion events and define a relationship between the transports and the likelihood of a Kuroshio Intrusion event. Kuroshio intrusions tend to occur when the transport of the Kuroshio east of Taiwan is low (Figure 8). The primary cause of the fluctuations in the transport of the Kuroshio east of Taiwan is the westward propagation of large eddies (Zhang et al., 2001).

The large intrusions of the Kuroshio onto the shelf extend $90 \mathrm{~km}$ or more shoreward of the shelf-break and move cyclonically away from the core of the Kuroshio before crossing the 

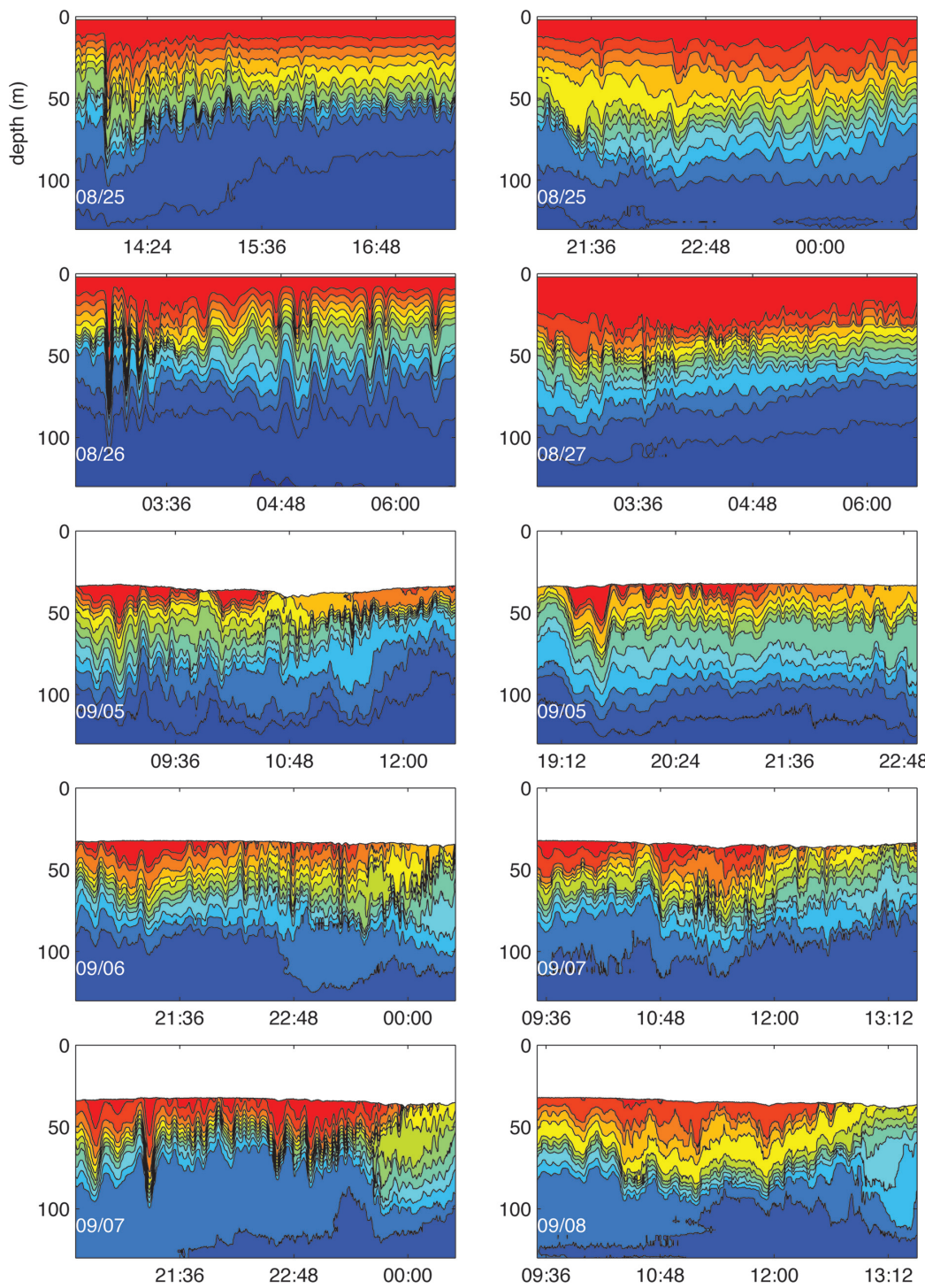

Figure 7. Selected time series from a mooring at the $130 \mathrm{~m}$ isobath near the shelf-break during time periods of active non-linear internal waves. Figure taken from Duda et al., this issue.

shelf-break. The large intrusions occur between Mien-Hua Canyon and North Mien-Hua Canyon. In contrast, the smaller intrusions occur over a much larger along-shelf distance and involve cross-shelf penetration of $50 \mathrm{~km}$ or less. Velez-Belchi et al. shows that the primary factor determining whether an intrusion is large or small is the initial angle of incidence as the Kuroshio crosses the shelf-break. Near-perpendicular flow across the shelf-break 

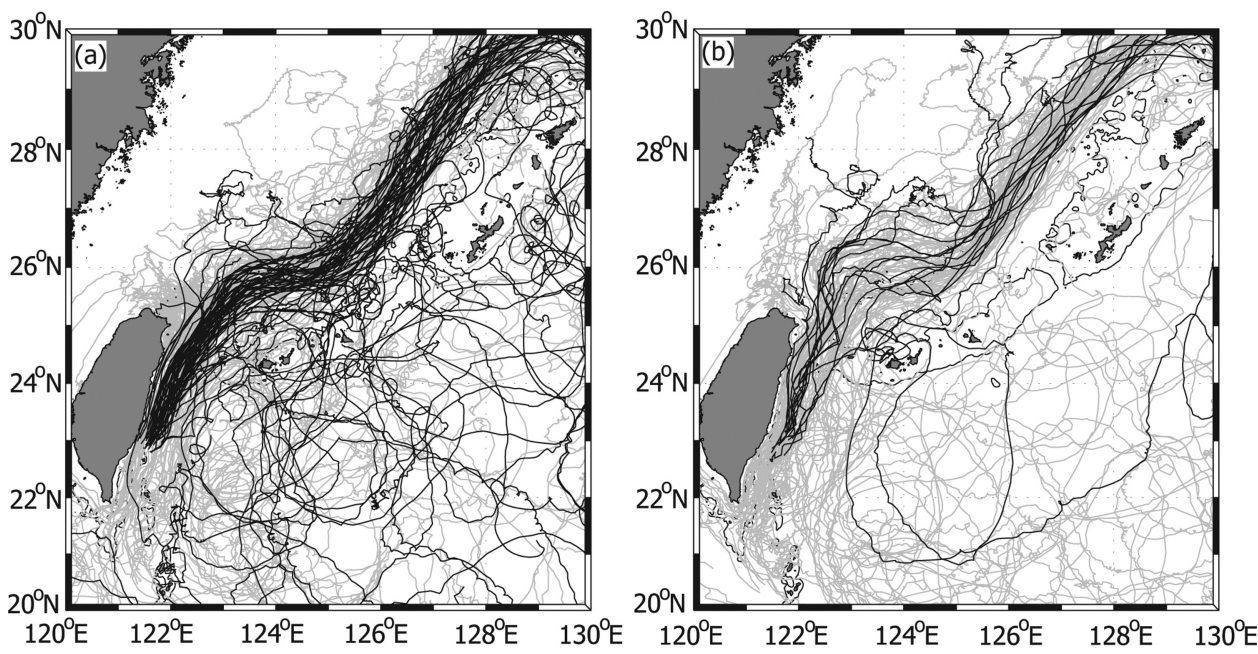

Figure 8. Trajectories for near surface drifters from high (left panel) and low (right panel) transport periods for the Kuroshio in the East Taiwan Channel. During times of low transport of the Kuroshio, large Kuroshio Intrusions onto the shelf tend to occur. The trajectories with the black lines are from deployments during the QPE study, between April, 2008 and Sept., 2009. Figure taken from BelezVelchi et al., this issue.

leads to large intrusions and substantial penetration across the shelf-break, while small angles of incidence lead to small intrusions and shallow penetration onto the continental shelf.

Further examination of the large Kuroshio intrusions indicates that the majority of events were preceded by the westward translation of a large cyclonic eddy into the path of the Kuroshio east of Taiwan. This has important implications for the predictability of the large Kuroshio intrusions on the shelf.

\section{Summary and future directions}

The QPE program succeeded in advancing our understanding of fundamental oceanographic processes northeast of Taiwan, both for internal waves and tides, as well as defining the factors leading to large Kuroshio Intrusions onto the continental shelf. By chance, many of the observations were made shortly after a devastating typhoon crossed Taiwan. A number of the papers address the remote impacts of Typhoon Morakot on the thermohaline structure overlying the continental shelf as well as the nutrient dynamics before and after the Typhoon. These are the most extensive post-typhoon observations over the continental shelf in the western Pacific, and nicely complement the deep-water observations of typhoon passage from the ITOP (Impacts of Typhoons on the Ocean in the Pacific) program (Pun et al., 2011). 
Further analysis of the extensive data sets is ongoing. In the near future, additional work on the quantification of model uncertainty relative to observed error probability density functions is proceeding. SeaSoar surveys, which include high-resolution observations of the buoyant plumes from the Typhoon Morakot induced runoff from the rivers on the western coast of Taiwan are being analyzed. Characterization of the Cold Dome circulation and predictability (Gopalakrishnan et al., 2013) will appear in the near future. Thus the efforts to understand the circulation and ecosystem dynamics in this complex region of the ocean northeast of Taiwan will continue.

Finally, we suggest three major thrusts for future work in this region, based on our experience with this multi-disciplinary international science program. First, there is a definite need for fast response hydrographic and biogeochemical observations after large typhoons (Hung and Gong, 2011). It is apparent from the studies in this issue that impacts from Typhoon Morakot extended over hundreds of kilometers and over weeks of time. The impacts in terms of nutrient transport onto the continental shelf were nearly comparable to the amount of nitrate needed to balance the nitrate budget in summer. It is clear further observations and modeling are needed to quantify the impacts after typhoons, as well as their impacts on ecosystem dynamics over the continental shelf and slope. While there are difficulties in doing these fast response studies, particularly in terms of research vessel scheduling, and the unpredictability of typhoon occurrences and intensity before the typhoon season starts, the scale of the impacts strongly argues for further studies along the lines of Hung et al. in terms of sampling before and after major typhoons. This is particularly important as climate change effects may lead to more frequent or more intense typhoons.

Second, the role of the canyons in the circulation northeast of Taiwan needs to be studied more closely. They may serve as conduits for exchange, and focused studies that relate Kuroshio variability to flow within the canyons would be very helpful. Because of the differences in geomorphology between Keelung, Mien-Hua and North Mien-Hua Canyons, it is possible that the cross-shelf velocities in the canyons may be significantly different in response to both Kuroshio impingement and synoptic wind forcing. This area serves as an outstanding natural laboratory to examine canyons and their impacts on the adjoining continental shelf.

Third, the profusion of potential generation sites for internal waves makes this region a natural area to study the interactions between internal wave trains from widely varying directions. Focused measurements which can identify wave trains from different directions and measure the non-linear displacements which may occur would be important in establishing the spatial and temporal variations in mixing and turbulence northeast of Taiwan. Since vertical mixing is an important aspect of getting nutrients into the euphotic zone, and thus directly impacts ecosystem dynamics, further work on internal tides and waves in this area would be very helpful in furthering our understanding of ecosystem dynamics in this region. 
The continental shelf and slope northeast of Taiwan are important for many reasons, including the commercial fisheries, the presence of oil and gas deposits, busy commercial shipping lanes and the frequent occurrence of typhoons. This is an area worthy of significant research efforts in the future.

Acknowledgments. We thank the National Science Council of Taiwan (R.O.C.) and the Office of Naval Research of the United States for supporting this international program. We thank C.-S. Chiu, D. Marble, B. Reeder, T. Paluszkiewicz and E. Livingston for their constant help and support at the Office of Naval Research. We appreciate the hard work and professionalism of the captain and crew of the Ocean Researcher I, Ocean Researcher 2, Ocean Researcher 3 and the $R / V$ Roger Revelle. Dean Ming-An Lee of National Taiwan Ocean University was a tremendous help throughout the program. We also thank the National Museum of Marine Science and Technology of Keelung for logistical support throughout the Intensive Field Program. We thank Pierre Lermusiaux for providing Figure 3 and Chris Linder for providing Figure 2. We also thank Magdalena Andres and two anonymous reviewers who provided very helpful comments in improving the clarity of the initial manuscript. GG was supported by ONR Grant N00014-07-01-0482.

\section{REFERENCES}

Chang, Y.-L.; C.-R. Wu and L.-Y. Oey, 2009. Bimodal behavior of the seasonal upwelling off the northeastern coast of Taiwan. Journal of Geophysical Research-Oceans, 114, C03027, doi:10.1029/2008JC005131.

Chern, C.-S.; J. Wang and D.-P. Wang. 1990. The exchange of Kuroshio and East China Sea shelf water. Journal of Geophysical Research-Oceans, 95, 16,017-16,023.

Chern, C.-S. and J. Wang. 1992. The influence of Taiwan Strait waters on the circulation of the southern East China Sea. La mer, 30, 223-228.

Duda, T.; A. Newhall; G. Gawarkiewicz; M. Caruso; H. Graber; Y.-J. Yang and S. Jan, 2013. Measured significant internal waves and internal tides northeast of Taiwan. Journal of Marine Research, 71(12), 47-82.

Gawarkiewicz, G.; S. Jan; P. Lermusiaux; J. McClean; L. Centuriani; K. Taylor; B. Cornuelle; T. Duda; J. Wang; Y.-J. Yang; T. Sanford; R.-C. Lien; C. Lee; M.-A. Lee; W. Leslie; P. Haley Jr.; P. Niiler; G. Gopalakrishnan; P. Velez-Belchi; D.-K. Lee and Y.-Y. Kim, 2011. Circulation and intrusions northeast of Taiwan: Chasing and predicting uncertainty in the Cold Dome. Oceanography, 24, $110-121$.

Gopalakrishnan, G.; B. Cornuelle; G. Gawarkiewicz and J. McClean, 2013. Coastal upwelling and Cold Dome analysis off northeastern Taiwan: a numerical study. Oceanography, in press.

Hsu, M.-K.; A. Liu and C. Liu, 2000. A study of internal waves in the China Seas and Yellow Sea using SAR. Continental Shelf Research, 20, 389-410.

Hsueh, Y; J. Wang and C.-S. Chern. 1992. The intrusion of the Kuroshio across the continental shelf northeast of Taiwan. Journal of Geophysical Research-Oceans 97, 14,323-14,330.

Hung, C.-C. and G.C. Gong, 2011. Biogeochemical responses in the southern East China Sea after typhoons. Oceanography, 24, 42-51.

Hung, C.-C.; C.-C. Chung; G.-C. Gong; S. Jan; Y. Tsai; K.-S. Chen; W. Chou; M.-A. Lee; Y. Chang; M.-H. Chen; W.-R. Yang; C.-J. Tseng and G. Gawarkiewicz, 2013. Nutrient supply in the southern East China Sea after Typhoon Morakot. Journal of Marine Research, 71(1-2), XXX-XXX.

James, C.; M. Wimbush and H. Ichikawa, 1999. Kuroshio meanders in the East China Sea. Journal of Physical Oceanography, 29, 259-272. 
Jan, S.; D. D. Sheu and H. M. Kuo. 2006. Water mass and throughflow transport variability in the Taiwan Strait. Journal of Geophysical Research-Oceans, 111, doi:10.1029/2006JC003656.

Jan, S.; C.-C. Chen; Y.-L. Tsai; Y.-J. Yang; J. Wang; C.-S. Chern; G. Gawarkiewicz; R.-C. Lien and J.-L. Kuo, 2011. Mean structure and variability of the Cold Dome northeast of Taiwan. Oceanography, 24, 100-109.

Jan, S.; J. Wang; Y.-J. Yang; C.-C. Hung; C.-S. Chern; G. Gawarkiewicz; R.-C. Lien and L. Centurioni, 2013. Observations of a freshwater pulse induced by Typhoon Morakot off the northern coast of Taiwan in August, 2009. Journal of Marine Research, 71(1-2), 19-46.

Johns, W. E.; T.N. Lee; D. Zhang; R. Zantopp; C.T. Liu and Y. Yang. 2001. The Kuroshio East of Taiwan: Moored Transport Observations from the WOCE PCM-1 Array. Journal of Physical Oceanography, 31, 1031-1053.

Klymak, J.; R. Pinkel; C.-T. Liu; A. K. Liu and L. David, 2006. Prototypical solitons in the South China Sea. Geophysical Research Letters, 33, doi:10.1029/2006GL025932.

Lee, H. S.; T. Yamashita; J. R.-C. Hsu and F. Ding, 2013. Integrated modeling of the dynamic meteorological and sea surface conditions during the passage of Typhoon Morakot. Dynamics of Atmospheres and Oceans, 59, 1-23.

Lee, T.; W. Johns; C.-T. Liu; D. Zhang; R. Zantopp and Y. Yang, 2001. Mean transport and seasonal cycle of the Kuroshio east of Taiwan with comparison to the Florida Current. Journal of Geophysical Research-Oceans, 106, 22,143-22,158.

Lermusiaux, P.F.J.; C.-S. Chiu; G.G. Gawarkiewicz; P. Abbot; A.R. Robinson; R.N. Miller; P.J. Haley; W.G. Leslie; S.J. Majumdar; A. Pang and F. Lekien. 2006. Quantifying uncertainties in ocean predictions. Oceanography 19, 90-103.

Lermusiaux, P.F.J.; J. Xu, C.F. Chen; S. Jan; L.Y. Chiu and Y.-J. Yang. 2010. Coupled oceanacoustic prediction of transmission loss in a continental shelfbreak region: Predictive skill, uncertainty quantification and dynamical sensitivities. IEEE Journal of Oceanic Engineering 35, 895-916.

Lien, R.-C.; T. Sanford; S. Jan; M.-H. Chang and B. Ma, 2013. Internal tides on the East China Sea continental slope. Journal of Marine Research, 71(1-2), 151-186.

Liu, A.; Y. Chang; M.-K. Hsu and N. Liang, 1998. Evolution of nonlinear internal waves in the East and South China Seas. Journal of Geophysical Research-Oceans, 103, 7995-8008.

Liu, K.K.; G.-C. Gong; S. Lin; C.Y. Yang; C.L. Wei; S.-C. Pai and C.-K. Wu. 1992. The year-round upwelling at the shelf break near the northern tip of Taiwan as evidenced by chemical hydrography. Terrestrial Atmospheric and Oceanic Sciences 3, 243-275.

Pun, I.; Y.-T. Chang; I.-I. Lin; T.-Y. Tang and R.-C. Lien, 2011. Typhoon-ocean interaction in the western North Pacific. Part 2. Oceanography, 24, 32-41.

Rainville, L. and R. Pinkel. 2004. Observations of energetic high-wavenumber internal waves in the Kuroshio. Journal of Physical Oceanography, 34, 1495-1505.

Ramp, S. and T.-Y. Tang, 2011. A history of Taiwan/US oceanographic research in the South China Sea. Oceanography, 24, 16-23.

Shroyer, E. L.; J. N. Moum and J. D. Nash, 2010. Energy transformations and dissipation of nonlinear internal waves over New Jersey's continental shelf. Nonlinear Processes in Geophysics, 17, 345360.

Tang, T.-Y.; Y. Hsueh; Y.-J. Yang and J.-C. Ma. 1999. Continental slope flow northeast of Taiwan. Journal of Physical Oceanography 29, 1,353-1,362.

Tang, T.-Y.; J.H. Tai and Y.J. Yang. 2000. The flow pattern north of Taiwan and the migration of the Kuroshio. Continental Shelf Research 20, 349-371.

Tsai, Y.; C.-S. Chern and J. Wang. 2008. Typhoon induced upper ocean cooling off northeastern Taiwan. Geophysical Research Letters 35, doi:10.1029/2008GL034368. 
Tsai, Y.; C.-S. Chern; S. Jan and J. Wang, 2013. Numerical study of Cold Dome variability induced by Typhoon Morakot (2009) off northeastern Taiwan. Journal of Marine Research, 71(1-2), 109-132. Velez-Belchi; P., L. Centurioni; D.-K. Lee; S. Jan and P. Niiler, 2013. Eddy induced Kuroshio Intrusions onto the continental shelf of the East China Sea. Journal of Marine Research, 71(1-2), 83-108.

Zhang, D.; T.N. Lee; W.E. Johns; C.T. Liu and R. Zantopp. 2001. The Kuroshio East of Taiwan: Modes of Variability and Relationship to Interior Ocean Mesoscale Eddies. Journal of Physical Oceanography, 31, 1054-1074.

Received: April 4, 2013; Revised: April 21, 2013. 